\title{
Research
}

\section{Using Metadiscourse to Improve Coherence in Academic Writing}

\author{
Jeremy F. Jones \\ University of Canberra, Australia
}

\begin{abstract}
One potent effect of the globalisation of English is the huge increase in the number of non-native English speakers (NNSs) undertaking university courses in English-speaking countries. There they study alongside native speakers (NSs), compared with whom they are at an obvious disadvantage. Analysing one essay by a NNS at an Australian university, this paper confronts a common and very significant challenge that such students face: difficulty with constructing a coherent argument. It probes this difficulty with particular reference to the techniques of reader-based writing embodied in the concept of metadiscourse. Possible remedies will be proposed to help the student, both for the short and long term.
\end{abstract}

People speak of English as a "global language," by which they mean a commonly accepted form of communication free of national and international variation. This is the lingua franca whose adoption allows Cambodians to talk to Swedes and Swedes to Mexicans. However, even within global English, there appear to be variations, for example between English for Business and English for Academic Purposes. Indeed, the field of English for Specific Purposes has evolved in TESL and TEFL to accommodate such differences.

This paper is situated within and is a contribution to the sub-discipline of Academic English, and in particular, academic writing. The genres of academic writing in English are immensely important in the world, since non-native English-speaking (NNS) academics, in common with their native English-speaking (NS) colleagues, have to learn to communicate in this English if they wish to publish and become known in the international community of their field. Academic writing in English is equally important for NS and NNS students who wish to succeed in English-medium higher education, because assessment is, in most disciplines, mainly by writing. Further, NNS students might be studying English to gain entry to an Englishmedium university; they, too, have to acquire the "global" skills of academic writing with a view to passing an international gatekeeping proficiency test, e.g., IELTS or TOEFL.

Unless they are close to bilingual, NNSs must struggle hard to present acceptable writing. As Canagarajah (2002) observes, "we shouldn't be surprised that L2 students fall short when L1 writing is treated as the norm or point of reference" (p. 12). Even if NNSs' grammar, syntax, 
and vocabulary range are of a relatively high standard, they still have to master the genre demands of their discipline.

Essential to academic writing is coherence. The present paper is a contribution to research on coherence, which is acknowledged to be "difficult to teach and difficult to learn" (Lee, 2002, p. 135). Coherence suggests that the ideas in the writing hold together. In this way, "the reader can follow the overall position that the writer takes, the arguments that are given to support the writer's position, and the evidence that the writer provides in support of these arguments" (Paltridge, Harbon, Hirsch, Shen, Stevenson, Phakiti, \& Woodrow, 2009, p. 34). The reference here to the central role of the reader in the definition of coherence foreshadows the emphasis of the argument in this research on the awareness of the reader's needs in effective academic writing.

By way of a case study of a particular NNS student's essay, the paper will throw into relief the degree to which the writer achieves coherence and show that the cause of her occasional loss of coherence may lie in a failure to adopt an approach that is responsible to the reader. It will then offer a pathway to helping her towards revision and coherence, a pathway given by the concept of metadiscourse.

The inquiry will, it is hoped, be illuminating for academics who seek a closer understanding of their NS and NNS students' writing behaviour and particularly the reasons for loss of coherence. Their perceptions, feedback to students, and even assessment may be better informed by such understanding. Teachers of academic writing may benefit likewise from the new insights yielded by the research, perhaps especially those related to reader-based writing, which have implications for writing pedagogy.

\section{Conceptual Background}

Although there are today many approaches to the study of academic writing, the field uniformly draws on two powerful concepts: contrastive rhetoric $(C R)$ and genre analysis. $C R$ is relevant to this study since it highlights differences of rhetorical convention between a writer's first and second languages; genre analysis is significant because it serves to define the features of the genres that academic writers need to grasp.

Contrastive rhetoric and academic writing. The essence of $C R$ is that each language is unique in its rhetorical aspects; research in CR focuses on rhetorical differences across cultures. In second and foreign language education, where such research has found its primary audience, CR suggests that differences between the discourse characteristics of learners' first and second languages are responsible for their difficulties in acquiring discourse patterns in their second language. This was the view of Kaplan (1966), the pioneer of CR, who analysed the paragraphs of essays by ESL students from varying cultures to demonstrate the way in which first language rhetorical structures figured in the second language writing.

CR had a great deal of influence on translation studies and second language pedagogy, informing teachers about cultural preference in the writing approaches of their students: "With this knowledge, teachers are better able to prepare ESL/EFL students to write for L2 audiences, which often have different expectations about organization, style, and appropriateness of content" (Connor, 1998). Teachers may learn, for example, that Finns and Japanese tend not to state their thesis at the start of the writing, leaving it until later in the text (Connor, 1998). Connor (1998) points out that Finnish writers are not reader-friendly, as they do not use transitions between paragraphs; they "let the facts speak for themselves." Hinds (1987) claims 
the same features for Japanese writing, in which it is the task of the reader to construct meaning. Modern Chinese, he insists, is more like English in being more reader-friendly.

However, CR is subject to appreciable debate. Even as Kaplan and his followers have revised and adapted the original thesis to counter charges of ethnocentricity and cultural stereotyping, others have produced research results that undermine CR. Kubota (1998, cited in Casanave, 2004), for example, undertook a study of 46 expository and persuasive essays written by Japanese students. Half were in English and half in Japanese. She found no uniform evidence of indirectness or digression, said to be characteristics of Japanese style, in the writing. Some of the students followed the CR stereotype and, in English, transferred it to their writing; many others did not do this. Kubota surmises that a number of variables were at work in her subjects' writing performance, including low competence in first language writing, the general standard of their second language, and the amount of experience they had in writing in the second language.

Indeed, these possible factors are the type that opponents of CR cite as responsible for ESL writing difficulties. Negative transfer of rhetorical organisation alone cannot explain them. For the purposes of the present research, Casanave's (2004) judgment on CR is resonant.

Summarising research contributions to the decades of debate on $\mathrm{CR}$, she concludes that "many of the problems that L2 students have with writing parallel those that L1 writers have" (p. 54). NS and NNS students alike will have trouble putting together the required elements of, for example, an academic essay if they have little experience of the genre.

Genre theory and academic writing. To be sure, genre, culture-specific as it may be, is what academic students must strive to master. Every genre, as a specific text type, has a body of formal features that distinguish it from another genre - a laboratory report from a book review, for instance. According to Swales (1990, p. 58), "Exemplars of a genre exhibit various patterns of similarity in terms of structure, style, content and intended audience." Teachers of academic writing have to know such patterns to ground their courses in the texts that the students will have to write in their target contexts.

It is important to concede that academic writing is not one genre. Across the disciplines there are so many differences in writing conventions that it makes little sense to treat academic writing as an undifferentiated genre. Indeed, in light of such diversity, it is arguable that no service course in academic writing could accommodate all the genre demands of the disciplines: students themselves should be encouraged to acquire mastery of the genre or genres of their field (Hyland, 2000).

However, there is a strong case for embracing the essay as a genre that crosses disciplinary boundaries. The great majority of students in the subject "Academic English," from which the sample in this paper was drawn, have to write assignments that take the form of essays. If they do not write essays as such, they nevertheless have to "write in essay-like ways, expressing a degree of critical thinking and sustaining a coherent, reasoned argument (Jones, 2007, p. 132). Certainly, academic English courses that prepare students for writing in their chosen discipline or support them once admitted commonly favour the essay as the genre that offers the most help for them. For example, an extremely popular modern textbook, Writing Academic English, by Oshima and Hogue (2006), presents mastery of the essay form as its goal.

In the academic setting, an essay is an argument that proceeds from introduction through body to conclusion. The body contains the force of the argument mediated through explanations, 
comparisons, examples and evidence, and "it is here that the bulk of the marks lie" (MorleyWarner, 2009, p. 35). Indispensable to the effectiveness of an essay is logical order, which constitutes the essence of coherence.

\section{Methodology}

This research may be regarded as proceeding along the lines of a case study, where the case is a "single instance of a class of objects or entities" (Nunan, 1992, p. 79). The case study is an inquiry into this single instance in the context in which it appears. In this study, the single instance is the essay for analysis, the results of which will enhance understanding of a particular problem in learning and teaching; the context is an Australian university, but more particularly a subject for credit in which students learn and practise academic skills that will help them in their mainstream subjects.

Essay writing is an essential part of the subject. Data, in the form of one sample essay, was drawn from the writing component and was not elicited by the researcher, but came out of a scheduled assignment. The student gave permission for her work to be used for research.

As with all small-scale studies, the matter of generalisability arises. We cannot generalise beyond the sample under investigation to a wider population. However, consistent with the principles of case study, the researcher does not claim that what has been discovered is true of the population in general; rather, he claims that the understanding gained from the research should illuminate issues for other researchers and practitioners (Allright \& Bailey, 1991). This research is therefore undertaken on the assumption that its readers - university educators and teachers of academic writing - will view the findings as holding true for, and offering useful insights into, the students they have.

\section{Sample and Students}

As mentioned above, the essay for analysis (see Appendix A) has been taken from a subject called "Academic English" which intends to improve academic skills, especially writing skills, which students need in their mainstream courses. Such subjects are common in universities in the English-speaking world these days. The chosen essay is not demonstrably "typical" of the quality of writing in the subject, which usually presents a range of competence, but it plainly exemplifies the difficulties of making a coherent argument.

For the purposes of this research, the NNS is re-named Maria; she is in her early 20s and comes from South America. When she wrote her essay, she had been in Australia for just over two years and was a first-year student. A distinctive feature of Maria is that she had studied English writing as part of the English proficiency requirement for university admission. Writing for her was a subtest of IELTS.

Since the essay belongs to a learning progression, it is important to give information about it in the context. It responds to a task set in the middle of the semester; thus, Maria is not a novice in the study of academic writing. She has benefited, to one extent or another, from instruction in the definition of an essay, brainstorming a topic, planning overall structure, writing an outline and introduction, note-taking from reading, and referencing. The essay is a first attempt in the "practice" stage and also represents the standard of writing competence that the student is offering lecturers in her mainstream subjects. 


\section{Approach to Analysis}

Criteria for analysis of the text derive from the definition of the genre essay itself and of coherence, as set out earlier. The analysis pays attention to the extent to which the writing displays logical order, its ideas hanging together.

It may be said that coherence subsumes cohesion, another key term for the analysis. Cohesion is coherence at a "local level," in relationship between sentences: "Think of cohesion as pairs of sentences fitting together in a way two pieces of a jigsaw do" (Williams, 2007, p. 80). Among the most important manifestations of cohesion are transition signals (however, as a result, for example, etc.). Repetition of key nouns and using pronouns to refer back to key nouns also promote cohesion. If any one of the above features is missing, the reader may fail to see connections between ideas.

Failing to see connections could cause just temporary annoyance since the reader may still infer the meaning and sense the flow of an argument. On the other hand, absence of connections could result in severe confusion. It may be said, then, that there are two levels of non-coherence: 1 ) when links are missing but the reader's ultimate comprehension is not threatened; and 2) when links are missing and the reader cannot follow the ideas. In the first case, the text is easily remediable, for example, with the addition of transition signals. In the second, a remedy is hard to see, and some significant rewriting is needed. Part of the analysis will concentrate on an instance of the latter in Maria's writing.

Apart from evaluating the text for coherence in its various facets, it is necessary to consider the quality of grammar, because if the grammar is of such poor quality that the reader cannot pick up the meaning, then coherence is lost.

\section{The Task}

Students, Maria among them, were asked to write an essay of between 1,000 and 1,200 words on the following topic:

To many people, the term Globalisation means Americanisation. This is because modern technology has allowed American products, including food, clothing, music, and films, to reach people all over the world. Some people see this aspect of globalisation as a threat to their traditions and values.

To what extent does globalisation threaten the traditions and values of some countries?

The students understood that they would need to search resources for ideas relevant to their approach to the topic and show evidence of such reading in the writing. Thus, they would demonstrate their skill in managing references. Five or six references were to be included in the text and set out as entries in the appropriate style in a list at the end.

\section{Analysis}

What follows is an analysis, with a focus on matters of coherence, of Maria's essay. Two subheadings are used: "Grammar" and "Coherence."

Although the analysis brings to light what is hoped to be sufficient evidence of the writer's degree of coherence to make credible generalisations about the causes of and possible 
remedies for any difficulties she has, it cannot be comprehensive, and much more may be said about this essay than appears in these few pages.

\section{Grammar}

With the sort of errors that Maria makes, the reader recognises the hand of a NNS. The errors are numerous. Prominent are faulty verb forms, for example, will explored (Paragraph 1) and to identified (Paragraph 2), and faulty word forms, for example, conscience efforts (Paragraph 4). Syntactic difficulties occur from time to time, as in "Globalization is driven by western adventurers had made ...," where there are two main verbs. Though the grammar causes strain for the reader, it does not overwhelm the general coherence of the essay.

\section{Coherence}

The opening paragraph serves as an indication of the writer's likely control of the topic and essay structure. Maria does not make a particularly auspicious start: "Since the history and introduction of new technologies ..." However, despite the awkwardness of expression, the paragraph offers a reasonable introduction. Maria states a clear purpose, legitimately narrows the focus to "values" in Africa and Australia, and foreshadows a point of view.

This limiting of coverage promises rhetorical control. Indeed, Maria sustains her two major subtopics, summarises her major points in Paragraph 7, and reserves space towards the end for an argument on the merits of globalism as opposed to globalisation.

One weakness is that she does not take up the concept of Americanisation at all. Also, it may be said her strident expression of a point of view and remedy for the effects of globalisation go beyond the requirements of the essay topic, which has the ultimate form of a "To what extent ..." question; nevertheless, a lecturer might appreciate this indication of more adventurous critical thinking.

Further, Maria occasionally stumbles in one aspect of coherence of argument, that is, the sense in which assertion and evidence hang together. For example, Maria states an opinion without support in Paragraph 3: "The extent [of] threats of globalisation are self evident in African countries"; in Paragraph 5, she makes a connection between technology and social decline, but does not establish how one is the reason for the other. There are also unsupported claims in the following paragraph about big banks encouraging online shopping with the result of reduced "socialization." The evidence for her claims may lie in her various cited references; if so, she is not representing her reading effectively in her writing.

Maria makes a noticeable attempt to form cohesive ties within paragraphs, especially with respect to transition signals. She confidently exploits conjunctions such as however and therefore. In Paragraphs 2 and 3, four such words are used. Paragraph 7 is skilfully held together by an "on the one hand ... on the other" structure. But her skill fails her in Paragraph 4 , where the four sentences are not explicitly connected to one another. The disconnection is especially abrupt between the second and third sentences, the latter introducing a new subtopic. These separate sentences may be "chunks" that Maria has imported from her reading and does not know how to integrate.

Likewise, in the last two sentences of Paragraph 6, there is a dislocation: no link guides the reader from "reduced socialization" to the point about globalisation as a "reality check." In the first of these two sentences, the part beginning with "and the individual when is not logger need ..." is a breakdown of sense. It is then impossible to understand the "However" she 
introduces in the final sentence, and the following idea cannot be reconciled to whatever meaning comes through in the rest of the paragraph.

The flow from one paragraph to the next in Maria's essay is generally smooth. Between the end of Paragraph 2 and the start of Paragraph 3, however, the reader has to make a sudden leap as the writer embarks on her discussion of globalisation in Africa without any discourse marker, such as To begin with . ..., or introductory clause or sentence. But after this point, she shows appreciable competence in her linking. For example, she connects Paragraph 4 to Paragraph 3 using the expression "such a radical undermining ..." to link back to and deepen the last idea of the previous paragraph.

In sum, although Maria has a number of skills as a writer, she has significant flaws of the kind that she is likely to repeat in other writing unless she finds ways to improve. First, she has difficulty in providing evidence for her claims, which is sure to be regarded as a serious lapse of academic skill by an assessor. The reason for this difficulty may well lie in her limited ability to represent her sources. Second, she is capable of losing cohesion to the point of a breakdown of sense. This is the form of non-coherence that is hard to remedy merely with the addition of a word or two, and thus some rewriting is necessary.

\section{Towards Remedies}

A major question appears at this point: What can be done to overcome the problems of coherence that Maria has? Since coherence occurs when "the reader can follow" the argument and evidence (Paltridge et al, 2009, p. 34), seeking a solution in the notion of reader orientation makes sense. When Maria loses coherence, she is not being "reader-friendly."

Although the writer's relationship with the reader is hardly a new idea - and, as mentioned earlier, it has a place in the debates on CR - it is only in recent research that it has been given theoretical and empirical rigour. It is worth stressing that the implications of this research for the classroom have not fully reached writing pedagogy. Much of the research is associated with Ken Hyland and colleagues and their concept of "metadiscourse." This is a term that suggests the ways a writer or speaker, using discoursal features and text commentary, guides a reader's or listener's perception of a text. Crucial to metadiscourse, according to Hyland (2005), is the writer's conscious engagement with the reader:

Metadiscourse reveals the writer's awareness of the reader and his or her need for elaboration, clarification, guidance and interaction. In expressing an awareness of the text, the writer also makes the reader aware of it, and this only happens when he or she has a clear reader-oriented reason for doing so. (p. 17)

Embodying this principle is a classification scheme for metadiscourse resources that writers may put into practice. These may be placed in two categories:

1. Helping to guide the reader through the text, e.g., in addition, furthermore, but, however, thus, as noted above, according to $X$, in other words, that is, for example

2. Involving the reader in the text, e.g., might, may, perhaps, probably, in fact, definitely, unfortunately, surprisingly, it is clear that, I, we, my

(adapted from Hyland, 2005, pp. 49, 51) 
In light of metadiscourse, what specifically can be done for a student like Maria? As an example of helping her in the short term, one serious instance of her non-coherence is chosen for remedy: Paragraph 4, which suffers from disconnectedness between sentences and ideas. As regards the long term - helping her to retain metadiscourse strategies - some pedagogical techniques are also proposed.

\section{In the Short Term}

1. Consult with Maria on what she intends to say in the paragraph. ("It seems to be an effort to broaden the scope of the threat of globalization and introduce Australia as an example.")

2. Create a model paragraph by leading Maria through a rewriting of it. Try to preserve as many of her words and meanings as possible. Make links between the sentences. Appendix B offers an example of such a model, with the metadiscourse resources in bold.

3. Point out that the sentence beginning with "Globalization is driven by western adventurers ..." does not clearly fit the context. If Maria wants to keep the idea, she should go back to her source (assuming that the idea comes from one) and review whether the sentence has a place in the paragraph and how it can be integrated.

4. Point out the metadiscourse words - the words that make it easier for the reader to follow ideas from one sentence or part of a sentence to another.

\section{In the Long Term}

After Maria has successfully revised the non-coherent parts of her essay, perhaps along the lines suggested above, there is no certainty that she has "learnt," that in subsequent writing she will remember to be responsible to the reader or recognise reader-unfriendly text when she has written it. If she is in the hands of a writing teacher, whether in class or in private consultation, then she may be guided through specific techniques to help her learn metadiscourse features for the long term. Significantly, such techniques are reading-based. The advantages of learning metadiscourse features are manifold. Among them are that metadiscourse features increase the writer's presence in the text, making the writer more engaged with it; they enhance the persuasiveness and comprehensibility of a text; they signal the writer's "friendly" attitude to the reader; and, not least, they promote coherence and relate ideas clearly to one another (Hyland, 2005). Some techniques follow:

Text manipulation. Many teachers will know jigsaw reading, which takes the form of reassembling chunks of text, often paragraphs, that the teacher has jumbled. To emphasise the writer's perspective on the activity, Hirvela (2004) proposes that students be given the first part of the text intact as a "launching point" (p. 120) and then smaller fragments of the text - at word, sentence, or paragraph level - to reassemble. A student like Maria would profit from practice in joining sentences to recognise the linguistic as well as the thematic ties that unite them. In this activity, "the reader basically pretends to be a writer" with the result that "greater attention is paid to the operations of writing" (Hirvela, p. 19).

Another text manipulation activity involves actual writing. Students are offered draft texts for editing and reworking. An example of a text would be one in which the metadiscourse features have been removed; the student then has to supply acceptable missing links and discuss how the additions improve the reader-orientation of the text. According to Hyland (2005), this kind of focused task provides "plenty of scaffolded opportunities for students to see the rhetorical effects of metadiscourse items" (p. 187).

Concordancing. This, too, is a resource familiar to teachers of academic English, and there are several guides to using concordancing in the classroom (e.g., Thurstun \& Candlin, 1998). 
Although concordance tasks do not require production, they do emphasise the ways in which language is used in discourse context, and they encourage analysis of text in the sense that the student draws conclusions about such use. The tasks can be adapted to focus particularly on metadiscourse features. According to Hyland (2005), "Concordanced output provides authentic data for materials that concentrate attention on metadiscourse forms widely used in target genres" (p. 185). He recommends getting students to fill in the gaps in concordance printouts with the help of contextual clues. The students could also use a concordancer themselves to draw out metadiscourse features and make inferences about their behaviour.

Reading for writing. The final point on how to help Maria and students like her in fact does not offer a technique but rather some general pedagogical advice: Simply, get students of writing to read as much as possible, because reading will improve writing. This perspective is hardly new. "Good readers are good writers" is a timeworn adage (Hirvela, 2004, p. 2). However, it is only in the last two decades that research has closely connected the two skills, abandoning the distinction between reading as "passive" and writing as "active" (Hirvela, 2004 , p. 9). However, reading and writing still tend to be taught and learnt separately. Teachers "are not necessarily prepared to fully appreciate or recognise the various relationships that exist between the two skills" (Hirvela, 2004, p. 2).

A number of studies (e.g., Cumming, 1989; Elley, 1991; Ferris \& Hedgcock, 1998; Krashen, 1993; Tsang, 1996) have shown how learners develop their writing through voluntary, extensive reading. Writing ability is, to use Krashen's (1993) term, "acquired" through reading. Many writing skills may flow from this exposure to extensive reading, from grammatical to rhetorical. However, the learner must want to read extensively.

\section{Conclusion}

At the end of his book Metadiscourse, Hyland (2005) points out that metadiscourse is a new and growing field of inquiry, holding potential for richer description and explanation of communicative interaction. It is to be hoped that the present study realises some of this potential. It shows how a lack of relationship with the reader may be the cause of a writer's difficulties with coherence, and how the resources of metadiscourse may help the writer both in the short and long term. Such resources are for the teacher, too, of course, once she or he recognises all of its advantages.

\section{Author Note}

Jeremy Jones, TESOL and Foreign Language Teaching Program, the University of Canberra, Australian Capital Territory, Australia.

Correspondence concerning this article should be addressed to Jeremy Jones, TESOL and Foreign Language Teaching Program, the University of Canberra, ACT 2601, Australia. E-mail: Jeremy.Jones@canberra.edu.au 


\section{References}

Allright, D., \& Bailey, K. M. (1991). Focus on the language classroom: An introduction to classroom research for language teachers. Cambridge, England: Cambridge University Press.

Canagarajah, A. S. (2002). Critical academic writing and multilingual students. Ann Arbor, MI: University of Michigan Press.

Casanave, C. (2004). Controversies in second language writing: Dilemmas and decisions in research and instruction. Ann Arbor, MI: University of Michigan Press.

Connor, U. (1998). Contrastive rhetoric: Development and challenges. Studia Anglica Posnaniensia: International Review of English Studies. Retrieved from http://www.thefreelibrary.com/Contrastive+rhetoric\%3a+development+and+challenges -a093027779

Cumming, A. (1989). Writing expertise and second language proficiency. Language Learning, 39(1), 81-141. http://dx.doi.org/10.1111/j.1467-1770.1989.tb00592.x

Elley, W. B. (1991). Acquiring literacy in a second language: The effect of book-based programs. Language Learning, 41(3), 375-411. http://dx.doi.org/10.1111/j.14671770.1991.tb00611.x

Ferris, D., \& Hedgcock, J. (1998). Teaching ESL composition: Purpose, process, and practice. Mahwah, NJ: Lawrence Erlbaum.

Hinds, J. (1987). Reader versus writer responsibility: A new typology. In U. Connor \& R. B. Kaplan (Eds.), Writing across languages: Analysis of L2 text. Reading, MA: Addison Wesley.

Hirvela, A. (2004). Connecting reading and writing in second language writing instruction. Ann Arbor, MI: University of Michigan Press.

Hyland, K. (2000). Disciplinary discourses: Social interactions in academic writing. London, England: Longman.

Hyland, K. (2005). Metadiscourse. London and New York: Continuum.

Jones, J. (2007). Losing and finding coherence in academic writing. University of Sydney Papers in TESOL, 2(2), 125-148.

Kaplan, R. B. (1966). Cultural thought patterns in intercultural education. Language Learning, 16(1-2), 1-20. http://dx.doi.org/10.1111/j.1467-1770.1966.tb00804.x

Krashen, S. (1993). The power of reading. Englewood, CA: Libraries Unlimited.

Lee, I. (2002). Teaching coherence to ESL students: A classroom inquiry. Journal of Second Language Writing, 11(2), 135-159. http://dx.doi.org/10.1016/S1060-3743(02)00065-6

Morley-Warner, T. (2009). Academic writing is...: A guide to writing in a university context. Sydney, Australia: Association for Academic Language and Learning.

Nunan, D. (1992). Research methods in language learning. Cambridge, England: Cambridge University Press.

Oshima, A., \& Hogue, A. (2006). Writing academic English ( $4^{\text {th }}$ ed.). White Plains, NY: Pearson Longman.

Paltridge, B., Harbon, L., Hirsch, D., Shen, H., Stevenson, M., Phakiti, A., \& Woodrow, L. (2009). Teaching academic writing: An introduction for teachers of second language writers. Ann Arbor, MI: University of Michigan Press.

Swales, J. (1990). Genre analysis: English in academic and research settings. Cambridge, England: Cambridge University Press.

Thurstun, J., \& Candlin, C. N. (1998). Exploring academic English: A workbook for student essay writing. Sydney, Australia: NCELTR.

Tsang, W.-K. (1996). Comparing the effects of reading and writing on writing performance. Applied Linguistics, 17, 210-233. http://dx.doi.org/10.1093/applin/17.2.210 
Williams, J. M. (2007). Style: Lessons in clarity and grace ( $9^{\text {th }}$ ed.). New York, NY: Pearson Longman. 


\section{Appendix A \\ Maria's Essay}

(1) Since the history and introduction of new technologies around the world, globalization has contributed to some extent to help the individual to maximize their potential and creating different life standards. The extent threats of globalization thus to the cultural and traditional values is not only in some countries but the threats are global. This essay will explored to what extend globalization is threatening cultural and traditions values of family values, heritage, and spirituality in African and Australian societies and, concludes by embracing globalism as humanistic alternative to globalization.

(2) Short, 2001 looks to Globalization and has defined as a global process that has being linking one first world country and one-third world country, by introducing a high level of demands in new technologies. However, globalization has undermined the ability of many cultural and traditional values worldwide and individual potential to understand the real extent of threats of globalization. Therefore, it essential to identified the extent of threats of globalization when it comes to the individual, family and societies like Africa and Australia within the cultural and traditional values. Short, states that the heart of the culture involves the place or the country, language, religion, values, traditions and costumes to identified the links and threats of globalization worldwide.

(3) Globalization undermines African peoples' cultural and traditional values by imposing western values of individualism and consumerism culture. The extent threats of globalization are self evident in African countries. Globalization is a new process of colonization for African societies in the twentieth century as people are seems as a commodity rather than a human being. It denies African peoples' history, renouncing cultural values, and heritage (Akande, 2002). African people are seduce by millions dollars advertising to consume new socially unneeded constructed goods threatening the cultural and traditional values of the familiar and the old to be undermined. Consequently, globalization has eroded African peoples' community building capacity, community values, individual and family identities and minimizing social harmony. Thus, the end result of globalization on African people is that global integration can contribute to local disintegration of culture, and traditional values.

(4) Akande, (2002) argues that such a radical undermining of individuals' existing cultural and traditions values have a corrosive threat and impact of who they are, what they want, and what they respect. The threats of globalizations are more evident because attacks spirituality, values and faint and cultural and traditional values worldwide. Globalization is driven by western adventurers had made a conscience efforts to undermine the cultural and traditional heritage of various countries around the world. The extent of the threats of globalization is not only for African societies but also to countries like Australia.

(5) Australian society has being seduced by new technologies, which have being introduced by the new free economic market of globalization. The introductions of the latest technology is threatening Australian society as having access to services like more expensive mobile phones, Internet, latest music, and fast foods undermining family and relationships, religion values, respect and dignity. Ganz (2006) argues that Australian societies in particular youth people are spending more time with the electronic gadgets than socializing. Access to new mobile technologies is addicted and high costly is predicted that youth Australian will built a significant debt in the next 10 years. This new trend of communication based on peer pressure of consumerism latest mobile phones, digital TV, IPods and other electronic gadgets are health 
hazards threatening not only youth Australians' health, and income but also impacting on relationship with parents, grandparents and peers.

(6) Australian society outdoor culture has been threatening by big banks encouraging people to use credit cards to shopping online rather than going out to shopping at the markets.

Australian people have been seduced by believing that using plastic to do online shopping gives more choices on healthy produces and specials. The reality is that choices are limited, socialization in reduced and therefore, reinforcing individualism (Wright, 2006). Akande argues that Globalization is a reality check for many societies, and the individual when is not logger need for concern of living wealthy or poor in the world. However, globalization has made difficulties and differences in the life of people in countries like Africa and Australia loosing their cultural and traditional values (Akande, 2002).

(7) Akande, 2002. States that Globalization is a threat for African and Australian societies' cultural and traditional values. On the one hand African societies has had experienced over the last centuries colonization undermining its people history, heritage, individual and family identity, spirituality, cultural and traditional values. Now globalization is threatening African people is to become a commodity rather than a human being. On the other hand in Australian society cultural and traditional values are threatening by the seductive consumerism culture which encourage people to have high levels of debt, eroding socialization, and changing conventional communication and outdoor culture. The challenge is to create a new social movement to address the threats of globalization in the world (Cerny, 2002).

(8) Globalism is a humane alternative to globalization. Globalization can be addressed by introducing globalism which means recognizing mutual respect and careful treatment for all people and the environment. It promotes ethical values of active practice in every-day-life (Ritchie 1999). The embracing of globalism will required a new social movement to take action; commitment and leadership of governments; multinationals ethical business practices, stakeholders and policy makers in creating active communication to foster understating of sharing of resources and sustainability and mutual aid in times of needs. Implementation and practice of globalism are urgent needed to address the treats of globalization in humanity.

(9) Finally, a new social movement is paramount to raise awareness and alternatives of the extent of threats of globalization. The inhumane impact of globalization on societies has been outlined in this essay as a wake up call to take action in addressing the new challenge of humanity that is globalization. The anti-globalization movement needs the support of societies, families and individuals to eradicate globalization and embraced globalism as an alternative humane process. Community building capacities, sense of self, individual and family identity, are foundation of cultural and traditional values to sustain families, communities and societies. It is for the best interest of future generations to think locally and act globally to nurture local culture to nourish and sustain humanity' livelihoods only can be achieved by eradicating globalization.

\section{References}

Akande, W, 2002. The Drawbacks of Cultural Globalization: Yellow times November 10 , 2002. http:/www.globalpolicy.org/globalis/cultural/2002/1110cult.htm

Cerny, P, 2002. Globalization: Labour movement faces global challenges, firefighter January/ February2002. 
Ganz, M, 2006. Business: Generation Y Ringing up mega mobile bills. The Canberra Times Saturday, 01 of April 2006.

Ritchei, M, 1998. "Globalization vs. Globalism: Given internationalism a bad name." The implementation of the International Covenant on Economic Social and Cultural Rights.

http:/www.unhcr.ch/tbs/doc.nsf/(Symbol)/dca801dc8f077834802565f0004d7fb2? Op... $5 / 04 / 2006$

Short, J, R, 2001. Globalization dimensions: Space, place, and the contemporary world. Reaktion Books.

Wright, 2006. Business: Debit cards becoming the preferred way of spending. The Canberra Times Saturday, 01 of April 2006.

\section{Appendix B \\ Proposed Model Paragraph 4}

Akande (2002) argues that such a radical undermining of individuals' existing cultural and traditional values has a corrosive influence on who they are, what they want, and what they respect. However, the threat of globalization affects not only developing regions like Africa but also countries around the world, attacking spirituality and cultural and traditional values. One example of this threat may be found in Australia. 